\title{
Erratum to: Comparison of potential higher order reference methods for total haemoglobin quantification- an interlaboratory study
}

\author{
Claudia Frank ${ }^{1} \cdot$ Christine Brauckmann $^{1} \cdot$ Marie Palos $^{2} \cdot$ Christian G. Arsene $^{1}$ • \\ Joerg Neukammer ${ }^{3}$ - Maria Estela del Castillo Busto ${ }^{2}$. Sabine Zakel ${ }^{1}$ - Claudia Swart ${ }^{1}$ • \\ Bernd Güttler $^{1} \cdot$ Rainer Stosch $^{1}$
}

Published online: 29 May 2017

(C) Springer-Verlag Berlin Heidelberg 2017

\section{Erratum to: Anal Bioanal Chem}

DOI:10.1007/s00216-016-0176-7

The authors would like to call the reader's attention to the fact that unfortunately there was a mistake in the authorship of reference 27 in the original article. The correct reference is given below:

27. Sargent M., Harte R., Harrington C. Guidelines for achieving high accuracy in isotope dilution mass spectrometry (IDMS). Cambridge: Royal Society of Chemistry; 2002.

The online version of the original article can be found at http://dx.doi.org/ 10.1007/s00216-016-0176-7

Claudia Frank

Claudia.Frank@ptb.de

1 Physikalisch-Technische Bundesanstalt (PTB), Bundes allee 100, 38116 Braunschweig, Germany

2 Laboratoire national de métrologie et dessais (LNE), 1, rue Gaston Boissier, 75784 Paris Cedex 15, France

3 PhysikalischTechnische Bundesanstalt (PTB), Abbestraße 2-12, 10587 Berlin, Germany 